\title{
Comparative Study of Corrosion Characteristics of MCS and KS7 SS in Selected Acid Media
}

\author{
Ajide O. O.", Agara K. W \\ Department of Mechanical Engineering, University of Ibadan, Nigeria
}

\begin{abstract}
The challenges of corrosion in manufacturing industries and domestic sectors are enormous and have caused product loss, product contaminations, plants shutdown, loss of customer confidence and non durability of machineries. The objective of this study is to investigate and compare the corrosion resistance of medium Carbon steel (MCS) and KS7 stainless steel in selected acid media. The MCS and KS7 SS were exposed to $0.5 \mathrm{M}$ of $\mathrm{H}_{2} \mathrm{SO}_{4}, \mathrm{HCl}$ and $\mathrm{HNO}_{3}$ environment for 36 days. The weight loss was taken every 3 days in order to evaluate CPR. The results obtained showed that KS7 SS generally offers a better corrosion resistance than the MCS in the selected acids media. The conclusion that can be drawn from this study is that while MCS is found to be unsuitable alloy in sulphuric, nitric and hydrochloric acid environments, KS7 SS is a reliable choice material for fabrication of engineering machines and tools meant for utility in these media.
\end{abstract}

Keywords MCS, KS7 SS, CPR, $\mathrm{H}_{2} \mathrm{SO}_{4}, \mathrm{HCl}$ and $\mathrm{HNO}_{3}$

\section{Introduction}

The challenges of corrosion in domestic and industrial sectors are enormous. It is the major problem facing exploration, production and processing of oil and gas, transportation, food and construction industries. It is very vital to make appropriate selection of materials with proven corrosion resistance characteristics in the fabrication of machinery in these sectors. The relevance of steel alloy in equipments design and construction cannot be overemphasized due to its strength and other mechanical properties. There is need to ascertain the corrosion behaviour of alloy materials in order to determine their suitable applications in various media. Researchers are making significant progress in the corrosion study and characterization of different grades of steel alloys in different environments. Grajcar et al (2010) compared the corrosion resistance of two-new developed high manganese austenitic steels in $1 \mathrm{~N} \mathrm{H}_{2} \mathrm{SO}_{4}$ and $3.5 \% \mathrm{Nacl}$ solutions. The test results of this study showed the low corrosion resistance of high manganese steels in acidic and chloride media. The authors found that both $26 \mathrm{Mn}-3 \mathrm{Si}-3 \mathrm{Al}-\mathrm{Nb}-\mathrm{Ti}$ and $24.5 \mathrm{Mn}-$ 3.5Si-1.5Al-Nb-Ti manganese steel alloys are liable to general pitting corrosion especially and more intensively in the sulphuric acid solution. Rim-rukeh and Awatefe in 2006 studied the corrosion of a 10 -inch crude oil pipeline by analyzing the physico-chemical characteristics of the soil environment. The study of soil concentrations, $\mathrm{pH}$,

\footnotetext{
* Corresponding author:
}

getjidefem2@yahoo.co.uk (Ajide O.O.)

Published online at http://journal.sapub.org/ijmee

Copyright (C) 2012 Scientific \& Academic Publishing. All Rights Reserved temperature and other important soil parameters showed it to be clay soil environment. The corrosivity of the soil samples was evaluated using the AWWAC 105 numerical scale. A total sum index of 21 recorded implied that the soil tested was extremely corrosive for low carbon steel. The corrosion effect of orange fruit juice has been investigated through the study of the corrosion of carbon steel in citrus sinensis (Badmos and Ajimotokan,2009).Weight loss technique was used in which test coupons with known weight were immersed in the test media which are natural orange juice, orange juice with preservatives and water for a total exposure time of 10 days. The experimental results revealed that the corrosiveness of sweet orange juice relative to carbon steel were mainly a function of its acidity. The author concluded that the packed orange juice with preservatives was most corrosive followed by natural orange juice and water respectively. The influence of Phosphorus addition on the corrosion resistance of carbon steel for a flue gas desulphurization system was examined in 2010 (Kim et al). The authors employed electrochemical methods such as potentiodynamic polarization tests and electrochemical impedance spectroscopy (EIS) in $10 \mathrm{wt} \%$ sulphuric acid $\left(\mathrm{H}_{2} \mathrm{SO}_{4}\right)$ solution at room temperature. The results of the potentiodynamic measurements indicated that the addition of Phosphorus increased the cathodic hydrogen evolution reaction. The experimental results showed that Phosphorus has a degrading effect on the corrosion resistance of carbon steels in $\mathrm{H}_{2} \mathrm{SO}_{4}$ solution. This is due to the increase in the activity of hydrogen. Afolabi (2007) studied the corrosion behaviour and Stress Corrosion Cracking (SCC) of low and medium carbon steels in cassava and cocoa extracts by weight loss measurement and constant extension to fracture method 
respectively. The results obtained revealed that medium carbon steel is more susceptible to corrosion than low carbon steel in both media. SCC is also more in medium carbon steel than low carbon steel in the two media under study. These deductions are due to higher carbon content in medium carbon steel coupled with various aggressive corrosion constituents contained in these media. The author concluded that Hydrogen embrittlement, as well as carbon cracking is responsible for SCC of these materials in the agro-fluid media. The corrosion inhibition of mild steel in sulphuric acid by methionine (MTI) was investigated by Oguzie et al in 2007 using electrochemical techniques. The authors were able to study the effect of KI additives on corrosion inhibition efficiency. The results obtained showed that MTI inhibited the corrosion reaction by adsorption onto the metal/solution interface. An increase in inhibition efficiency was observed with increase in MTI concentration and synergistically increased in the presence of KI, with an optimum [KI]/ [MTI] ratio of $5 / 5$, due to stabilization of adsorbed MTI cations by means of AFM surface morphological images. The paper concluded that potentiodynamic polarization data suggest that the compound functioned via a mixed-inhibition mechanism. Corrosion resistance performance of welded joints in API5L-X52 pipe steel aged at $250{ }^{\circ} \mathrm{C}$ at various times was investigated under electrochemical technique such as tafel polarization, scanning electron microscopy (SEM) and transmission electron microscopy (TEM) studies (Vargas-Arista, 2011) .The results obtained from the electrochemical experiments which were performed in a solution of brine containing hydrogen sulphide at $25{ }^{\circ} \mathrm{C}$, showed an increase of the general corrosion rate in the weld bead, the heat affected zone and the base metal as the aging time was elapsed. The higher corrosion rate was due to the transgranular precipitation of fine nanoparticles of cementite and niobium carbide. The SEM examination of the corrosion products at the three different zones indicated the presence of oxide and sulphur of iron very brittle and porous on metallic surface. The largest increase in the amount of nanocarbides, lesser coarsening and the presence of corroding products with larger brittleness and porosity were responsible for the highest corrosion penetration rates recorded by the weld bead. Stainless steel is becoming important alloys due to its acceptable mechanical and corrosion characteristics. An intensive work has equally been done in the corrosion characterization of these alloys. Dai et al (2009) research paper focused on the effect of copper in the enhancement of corrosion resistance of $\mathrm{Cr}-\mathrm{Mn}$ stainless steel in 3.5\% Nacl. The major aim of the author was to improve the corrosion resistance of $\mathrm{Cr}-\mathrm{Mn}$ steel by alloy optimization methods characterization techniques such as Scanning Electron Microscopy (SEM) and Energy Disperse Spectroscopy (EDS) were employed to analyse the interface and phase composition of samples. The result of his findings shows that the addition of $\mathrm{Cu}$ enrichments within corrosion pits improves the corrosion resistance of $\mathrm{Cr}-\mathrm{Mn}$ steel in 3.5\% Nacl. The corrosion resistance of 18-8 stainless steel in cassava fluids containing principally hydrogen cyanide was studied by Oluwole et al (2009). The work simulated the effect of continuous use of this material in a cyanide environment where corrosion products are left in place.18-8 stainless steel was then subjected to cassava fluid environment for thirty days. The results obtained by the authors showed that 18-8 stainless steel was found appropriate for the fabrication of cassava processing machinery because of its very high corrosion resistance behaviour. The corrosion behaviour of nickel and stainless steel alloys in 3 and $5 \mathrm{~mol} / \mathrm{L}$ lithium hydroxide solutions under a hydrogen atmosphere at $95^{\circ} \mathrm{C}$ was studied by Graydon and Kirk (1990). Corrosion of Nickel 200 (UNS N02200) and the stainless steels 316 (UNS S31600), 316L (UNS S31603), and E-Brite 26-1 (UNS S44625) were experimented in two sets of immersion tests lasting 10 and 136 days. Corrosion rates were evaluated via weight loss while susceptibility to stress corrosion cracking was estimated using U-bends. Electron microscopy, x-ray spectrometry and mapping, and x-ray diffraction were employed in the corrosion analysis. The long-term corrosion rates were low for all the four alloys investigated (i.e less than $4 \mu \mathrm{m} / \mathrm{y}$ ) and no stress corrosion cracking was observed. The corrosion products on the stainless steels were a thin continuous layer of chromium oxide that provided the passivating shield. In situ synchrotron radiography has been employed by Ghahari et al in 2011 to observe the evolution of two-dimensional corrosion pits growing in stainless steel foils under electrochemical control in chloride solutions. The local current density along the boundary of a pit is directly measured from the radiographs. The authors back calculated the local metal ion concentration and potential drop inside the pit cavity are using transport equations and the requirement to maintain charge neutrality, giving the relationship between current density, solution composition and interfacial potential. According to this paper, preliminary comparisons shown qualitative agreement between the model and extracted data.200 series stainless steel has started attracting the attention of researchers, manufacturing engineers and steel vendors due to its unique mechanical characteristics and acceptable corrosion behaviour. In a recent article by Charles et al (2008), a new grade of the 200 series has been defined for the European market as a candidate alternative to austenitic grade AISI 304. This is because the new grade is designed to reduce the nickel content while still stabilizing the austenitic phase with combined copper and relatively low nitrogen and carbon contents. The experimental data of the newly designed grade were compared to the existing 300 and 400 series stainless steels. The conclusion of the authors was that the newly designed 200 grades have mechanical properties slightly superior to AISI 304 and its corrosion resistance property is also close to this alloy AISI 304.

\section{Materials and Methods}

\subsection{Chemical Analysis}


Table 1. Chemical Composition Analysis of Medium Carbon steel (MCS)

\begin{tabular}{|c|c|c|c|c|c|c|c|c|c|c|c|}
\hline \multicolumn{2}{|c|}{ Run } & $\mathrm{C}$ & \multicolumn{2}{|c|}{$\mathrm{Si}$} & $\mathrm{S}$ & \multicolumn{2}{|c|}{$\mathrm{P}$} & $\mathrm{Mn}$ & \multicolumn{2}{|c|}{$\mathrm{Ni}$} & $\mathrm{Cr}$ \\
\hline \multicolumn{2}{|c|}{1} & .3397 & \multicolumn{2}{|c|}{0.2191} & 0.0573 & \multicolumn{2}{|c|}{0.0620} & 0.8294 & \multicolumn{2}{|c|}{0.0960} & 0.1242 \\
\hline \multicolumn{2}{|c|}{2} & .3426 & \multicolumn{2}{|c|}{0.2204} & 0.0605 & \multicolumn{2}{|c|}{0.0597} & 0.8343 & \multicolumn{2}{|c|}{0.0961} & 0.1245 \\
\hline \multicolumn{2}{|c|}{ Avg } & .3411 & \multicolumn{2}{|c|}{0.2198} & 0.0589 & \multicolumn{2}{|c|}{0.0609} & 0.8318 & \multicolumn{2}{|c|}{0.0960} & 0.1244 \\
\hline Mo & V & $\mathrm{Cu}$ & W & As & $\mathrm{Sn}$ & $\mathrm{Co}$ & A1 & $\mathrm{Pb}$ & $\mathrm{Ca}$ & $\mathrm{Zn}$ & $\mathrm{Fe} \%$ \\
\hline 0.0188 & 0.0057 & 0.2066 & 0.0035 & 0.0056 & 0.0252 & 0.0088 & -0.0007 & 0.0001 & 0.0001 & 0.0035 & 97.9951 \\
\hline 0.0191 & 0.0058 & 0.2077 & 0.0035 & 0.0059 & 0.0262 & 0.0088 & -0.0007 & -0.0000 & 0.0001 & 0.0038 & 97.9816 \\
\hline 0.0189 & 0.0058 & 0.2071 & 0.0035 & 0.0058 & 0.0257 & 0.0088 & -0.0007 & 0.0001 & 0.0001 & 0.0036 & 97.9883 \\
\hline
\end{tabular}

Table 2. Chemical Composition Analysis of KS7 Stainless steel

\begin{tabular}{|c|c|c|c|c|c|c|c|c|c|c|c|}
\hline \multicolumn{2}{|c|}{ Run } & $\mathrm{C}$ & \multicolumn{2}{|c|}{$\mathrm{Si}$} & $\mathrm{S}$ & \multicolumn{2}{|c|}{ P } & $\mathrm{Mn}$ & \multicolumn{2}{|c|}{$\mathrm{Ni}$} & $\mathrm{Cr}$ \\
\hline \multicolumn{2}{|c|}{1} & 0.1099 & \multicolumn{2}{|c|}{9.3663} & 0.0150 & \multicolumn{2}{|c|}{0.0640} & .0512 & \multicolumn{2}{|c|}{0.3414} & 11.4664 \\
\hline \multicolumn{2}{|c|}{2} & 0.1105 & \multicolumn{2}{|c|}{0.3534} & 0.0187 & \multicolumn{2}{|c|}{0.0728} & .6255 & \multicolumn{2}{|c|}{0.3532} & 11.1139 \\
\hline \multicolumn{2}{|c|}{ Avg } & 0.1102 & \multicolumn{2}{|c|}{0.3598} & 0.0169 & \multicolumn{2}{|c|}{0.0684} & .7384 & \multicolumn{2}{|c|}{0.3473} & 11.292 \\
\hline Mo & $\mathrm{V}$ & $\mathrm{Cu}$ & $\mathrm{W}$ & As & $\mathrm{Sn}$ & $\mathrm{Co}$ & A1 & $\mathrm{Pb}$ & $\mathrm{Ca}$ & $\mathrm{Zn}$ & $\mathrm{Fe} \%$ \\
\hline-0.3414 & 0.0748 & 4.6323 & 0.0817 & 0.0246 & 0.0219 & 0.0444 & 0.0146 & 0.0236 & 0.0004 & 0.0340 & 71.8657 \\
\hline-0.0291 & 0.0731 & 4.0527 & 0.0800 & 0.0242 & 0.0229 & 0.0450 & 0.0121 & 0.0206 & 0.0003 & 0.0326 & 73.0176 \\
\hline-0.0306 & 0.0739 & 4.3425 & 0.0808 & 0.0244 & 0.0224 & 0.0447 & 0.0134 & 0.0221 & 0.0003 & 0.0333 & 72.4417 \\
\hline
\end{tabular}

The MCS was procured from the universal steel Limited, Ikeja, Lagos state while KS7 SS was bought from a stainless steel vendor in Nigeria. KS7 SS is one of the 200 series stainless steels manufactured by KAD Steel Rolling Mills, India. The chemical composition analysis of both MCS and KS7 SS were carried out at the Universal Steel Limited, Ikeja, Lagos state.

\subsection{Corrosion penetration rate (CPR) Measurements Using Weight Loss}

The MCS and KS7 SS were used as received condition. The samples were machined into cylindrical and rectangular pieces of $15 \mathrm{~mm}$ diameter and $41 \mathrm{~mm}$ long and $44 \mathrm{~mm}$ by $45 \mathrm{~mm}$ respectively. The sample surface were treated by abrading them through successive grades of silicon carbide papers of grades 60 and 120 grit, and finally on the $0.05 \mu \mathrm{m}$ emery cloth grade. They were rinsed in distilled water and then in acetone before drying. The prepared samples were stored in desiccators until when used for the experiments .After three days of storage; the coupons were immersed in $0.5 \mathrm{~mol} \mathrm{dm}^{-3}$ of $100 \mathrm{ml}$ of each of the three media (Sulphuric, Hydrochloric and Nitric Acids) for a period of 36 days. The corrosion coupons were removed from the corrosion environment with the aid of a tong. These were then properly cleaned in distilled water and dried with cotton wool. The dried samples were weighed with the electronic digital weighing balance and recorded. Weight loss measurements of coupons were recorded at interval of 3 days. The corrosion penetration rate (CPR) were calculated from weight loss analysis using the equation (1)

$$
C P R=\frac{K W}{\rho A t}
$$

Where $\mathrm{K}=$ constant $=3.45 \times 10^{6}$

$\mathrm{CPR}=$ Corrosion Penetration Rate in mils per year (mpy)

$\mathrm{W}=$ the weight loss in grams

$\mathrm{A}=$ Area of exposed specimen in $\mathrm{cm}^{2}$

$\mathrm{t}=$ time or duration of exposure in hours $\rho=$ Density of material in $\mathrm{g} / \mathrm{cm}^{3}$

\section{Results and Discussion}

\subsection{Results}

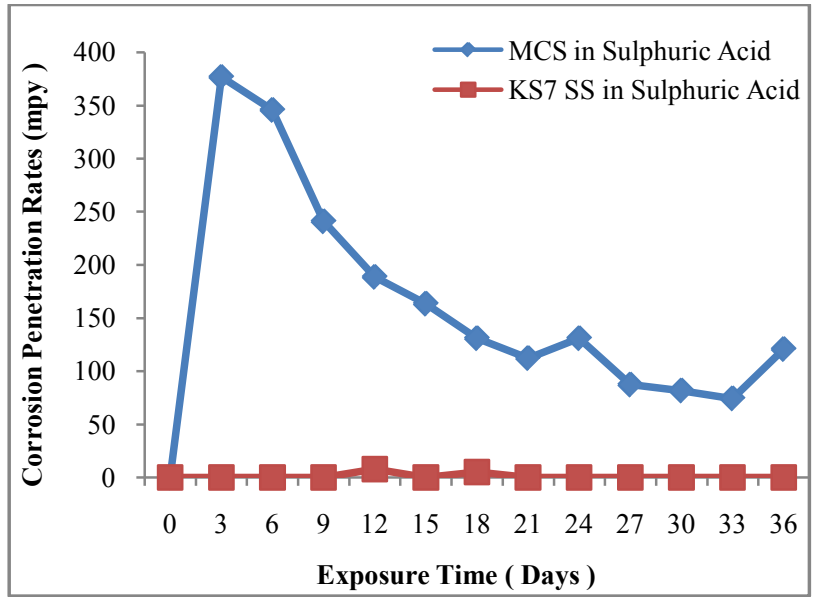

Figure 1. $\mathrm{CPR}$ of MCS and $\mathrm{KS} 7 \mathrm{SS}$ in $\mathrm{H}_{2} \mathrm{SO}_{4}$ Medium

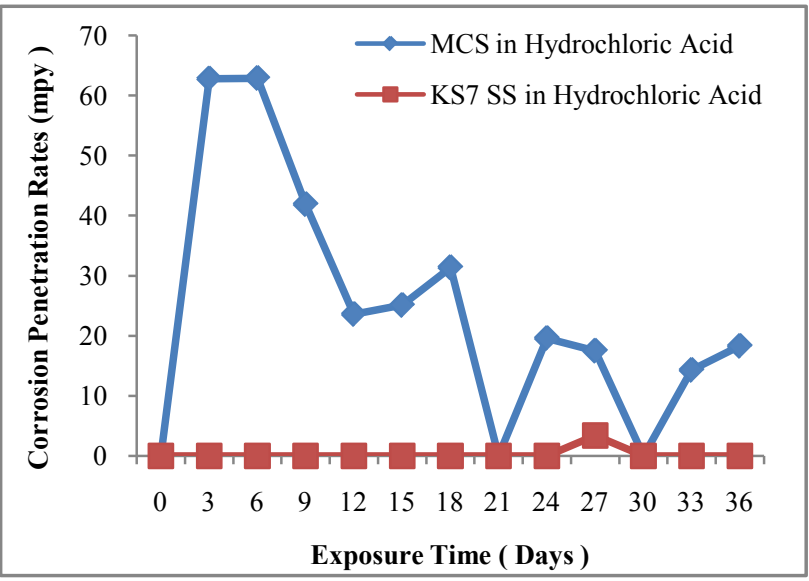

Figure 2. CPR of MCS and KS7 SS in $\mathrm{HCl}$ Medium 


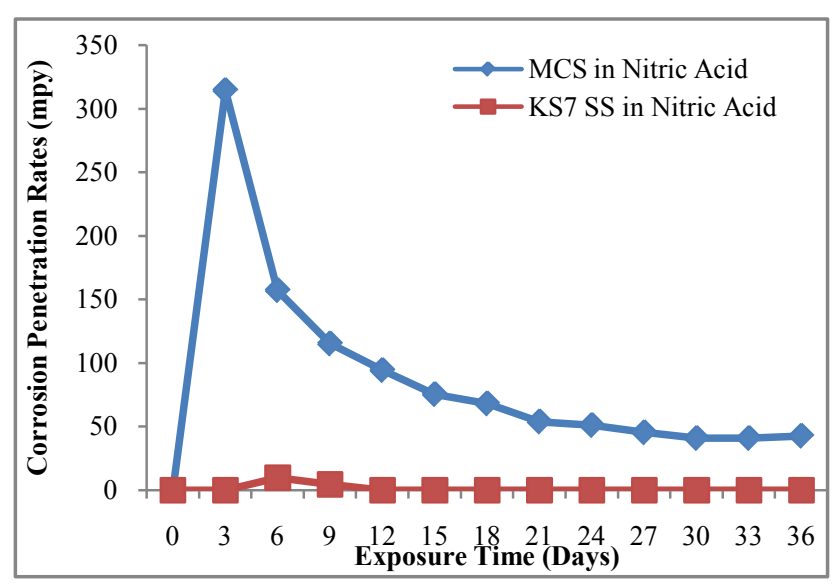

Figure 3. $\mathrm{CPR}$ of $\mathrm{MCS}$ and $\mathrm{KS} 7 \mathrm{SS}$ in $\mathrm{HNO}_{3}$ Medium

\subsection{Discussions}

Fig. 1 gives a description of the corrosion behaviour of MCS and KS7 SS in $0.5 \mathrm{M}, 100 \mathrm{ml}$ sulphuric acid. The corrosion penetration rates (CPR) of MCS was $3.767 \times 10^{2}$ mpy at the end of the 3rd day. At the end of the 6th day, there was a slight decrease of CPR to $3.457 \times 10^{2} \mathrm{mpy}$. This significant corrosion degradation continued throughout the 36 days .Except on the 24th and 36th days when it experienced an increase in CPR, a daily slight decrease in corrosion deterioration continued till the 33rd day. Between 33rd and 36th days, the CPR again picked up. Unlike MCS, KS7 SS shows a high corrosion resistance characteristic throughout the 36 days study period. With the exception of 12th and 18th days where an insignificant CPR of 7.8 mpy and $5.2 \mathrm{mpy}$ were experienced. Fig.1 evidently illustrates that KS7 SS has better corrosion resistance in $\mathrm{H}_{2} \mathrm{SO}_{4}$ environment compared to MCS. Similarly, fig. 2 shows a high degree of instability in the corrosion behaviour of MCS compared to KS7 SS where high resistance to corrosion degradation in $0.5 \mathrm{M}, 100 \mathrm{ml} \mathrm{HCl}$ medium.MCS experienced very significant corrosion deterioration throughout the 36 days with peak values of $6.28 \times 10^{1}$ mpy, $6.29 \times$ $10^{1} \mathrm{mpy}, 4.19 \times 10^{1} \mathrm{mpy}$ and $3.14 \times 10^{1} \mathrm{mpy} . \mathrm{KS} 7$ SS remained passive throughout the experimentation except on the 27th day when a little corrosion deterioration was experienced. The formation of a very strong passive layer of Chromium oxide is responsible for this high corrosion resistance characteristic. A minute depletion in the passive layer was the cause of small corrosion degradation which occurred in the 27th day. Obviously, KS7 SS is a very reliable alloy material in $\mathrm{HCl}$ environment compared to its MCS counterpart which exhibited a very poor corrosion performance in the same medium. In the same vein, fig. 3 illustrates the corrosion behaviour of MCS and KS7 SS in $0.5 \mathrm{M}$ $\mathrm{HNO}_{3}$ for a period of 36 days. MCS started experiencing corrosion degradation on the 3rd day with a CPR value of $3.143 \times 10^{2} \mathrm{mpy}$.This corrosion deterioration continued throughout the 36 days with a general gradual decrease in CPR values on the daily basis. Aside between 6th and 9th days when KS7 SS experienced minors CPR of 9.7mpy and $4.5 \mathrm{mpy}$, this alloy exhibited a characteristic of very high corrosion resistance throughout the experimentation period. Markedly, it can be deduced from fig. 3 that KS7 SS is better and highly reliable alloy material in nitric acid environment in comparison with MCS where very high corrosion degradation is noticeable. A passive film of Chromium oxide which acts as protective layer is responsible for this interesting corrosion resistance characteristic of KS7 SS.

\section{Conclusions}

This experimental study have obviously shown that MCS is generally unreliable and unsuitable alloy in the fabrication of machinery and tools for processing Sulphuric, Nitric and Hydrochloric acids ( or where these mineral acids exist as contaminants ). No doubt, this is due to its very high corrosion degradation characteristics. Interestingly, KS7 SS has a very promising corrosion resistance characteristics compared to MCS and therefore highly reliable and suitable alloy material for construction of machines, packaging containers, tools and engineering accessories meant to be utilized in these mineral acids media.

\section{REFERENCES}

[1] Afolabi A.S. (2007), Corrosion and Stress Corrosion Behaviour of Low and Medium Carbon Steels in Agro-Fluid Media. Leonardo Electronic Journal of Practices and Technologies (LEJPT), Vol.6, Issue 10, Pg.55-66.

[2] Badmos A.Y. and Ajimotokan A.A.2009.The Corrosion of Mild Steel in Orange Juice Environment. A technical Report with No: 2009-02 Written by Badmos and Ajimotokan of the Department of Mechanical Engineering, University of Ilorin, Nigeria.

[3] Charles J.,Mithieux J.D.,Krautschick J.,Suutala N.,Antonio S.J.,Van Hecke S. and Pauly T. (2008), A New European 200 Series Standard to Substitute 304 Austenitics? . Charles of the ArcelorMittal Stainless,France.

[4] Dai A., Zhang Y., Jin Y. and Xin W.2009. Effect of Copper on Corrosion Resistance of Cr-Mn Stainless in Chloride Solution. Journal of Jiangsu, University of Science and Technology (Natural Science Edition).TG171.The Authors are from School of Materials Science and Engineering, Zhenjiang 212003, China.

[5] Ghahari S. M., Krouse D. P., Laycock N. J., Rayment T., Padovani C., Suter T. Mokso, R., Marone F., Stampanoni M., Monir M and Davenport A. J.(2011) Pitting corrosion of stainless steel: measuring and modelling pit propagation in support of damage prediction for radioactive waste containers . Corrosion Engineering, Science and Technology, Volume 46, No.2, Pg. 205-211(7),Publisher: Maney Publishing.

[6] Grajcar A., Kolodziej S. and Krukiewic Z. 2010. Corrosion Resistance of High-Manganese Austenitic Steels. International Scientific Journal Published Monthly by the World Academy of Materials and Manufacturing Engineering. Volume 41, Issue 2, pg77-84. Archives of Materials Science and Engineering. 
[7] Graydon J.W. and Kirk D.W. (1990), Corrosion of Nickel and Stainless Steels in Concentrated Lithium Hydroxide Solutions. CORROSION-The Journal of Science and Engineering Vol. 46, Issue 12, 1021; doi:10.5006/1.3585050 (8 pages), NACE International.

[8] Kim M.J., Lee S.H., Kim J.G. and Yoon J.B. (2010), Effect of Phosphorous on the Corrosion Behaviour of Carbon Steel in Sulphuric Acid. Corrosion-The Journal of Science and Engineering, NACE International, Vol.66 Issue 12, ISSN-0010-9312.

[9] Oguzie E.E. Y. Li and Wang F.H.(2007), Corrosion inhibition and adsorption behaviour of Methionine on Mild steel in Sulphuric acid and Synergistic Effect of Iodide ion. Journal of Colloid and Interface Science 310 (2007) Pg.90-98, www.elsevier.com/locate/jcis
[10] Oluwole O.O., Atanda, P.O., Odekunbi O.A. and Odegbaju E.2009.Corrosion Behaviour of 18-8 Stainless Steel and Nickel-Plated Low-Carbon Steel in Cassava fluid. Journal of Minerals and Materials characterization and Engineering, Vol.8, No.10.pp803-811-2009.jmmce.org, printed in the USA.

[11] Rim-rukeh A. and Awatefe J.K. (2006), Investigation of Soil Corrosivity in the Corrosion of Low Carbon Steel Pipe in Soil Enviroment. Journal of Applied Sciences Research 2(8), Pg.466-469.INSInet Publications.

[12] Vargas-Arista B., Solis R. J., Angeles-Chavez C., Albiter A. and Hallen J.M. (2011), Deterioration of the Corrosion Resistance of Welded Joints in API5L X52 Steel Isothermally Aged. International Journal of Electrochemical Sciences., Vol. 6 Pg. $367-378$. 